MORE THAN HALF OF NEWLY DIAGNOSED RA PATIENTS ARE NOT CONVINCED OF THE NECESSITY OF RA MEDICINES: ASSOCIATIONS WITH RA CHARACTERISTICS, SYMPTOMS, AND FUNCTION IN THE CANADIAN EARLY ARTHRITIS COHORT (CATCH)

V. Ta' ${ }^{1}$, O. Schieir ${ }^{2}$, M. F. Valois ${ }^{1}$, G. Hazlewood ${ }^{3}$, C. Hitchon ${ }^{4}$, L. Bessette ${ }^{5}$, D. Tin $^{6}$, C. Thorne ${ }^{6}$, J. Pope ${ }^{7}$, G. Boire ${ }^{8}$, E. Keystone ${ }^{2}$, V. Bykerk ${ }^{9}$, S. J. Bartlett on behalf of CATCH Investigators. ${ }^{1}$ Mc Gill University, Montreal, Canada; ${ }^{2}$ University of Toronto, Toronto, Canada; ${ }^{3}$ University of Calgary, Calgary, Canada ${ }^{4}$ University of Manitoba, Winnipeg, Canada; ${ }^{5}$ University of Laval, Quebec City, Canada; ${ }^{6}$ Southlake Regional Health Centre, Newmarket, Canada; ${ }^{7}$ Western University, London, Canada; ${ }^{8}$ University of Sherbrooke, Sherbrooke, Canada; ${ }^{9}$ Hospital for Special Surgery, New York, Canada

Background: Although DMARDs are essential for early aggressive control of RA to reduce symptoms and disability, medication adherence is variable. Beliefs about the necessity of medications and safety concerns predict adherence and are modifiable. Objectives: To examine associations among RA medication necessity beliefs and concerns, sociodemographics, RA characteristics, symptom level and function in newly diagnosed RA patients.

Methods: Baseline data were analyzed from participants in the Canadian Early Arthritis Cohort (CATCH) who enrolled between 2017-2020 and completed the Beliefs about Medicine Questionnaire (BMQ) and PROMIS-29. All met ACR1987 or 2010 ACR/EULAR criteria and had active RA at enrollment. BMQ Necessity $(\mathrm{N})$ and Concerns $(\mathrm{C})$ scores were classified as high $(\geq 20)$ or low $(<20)$ and categorized into: Accepting $(\uparrow N \downarrow C)$; Ambivalent $(\uparrow N \uparrow C)$; Sceptical $(\downarrow N \uparrow C)$; and 4) Indifferent $(\downarrow N \downarrow C)$. Groups were compared using ANOVA and chi-square tests. Results: The 362 patients were mostly white $(83 \%)$ women $(66 \%)$ with a mean (SD) age of 56 (15), symptom duration of 6 (3) months, and $32 \%$ were obese $(\mathrm{BMI} \geq 30)$. More than half $(56 \%)$ were DMARD-naive or minimally exposed. Mean $\mathrm{N}$ and $\mathrm{C}$ scores were similar between men and women; $54 \%$ were classified as Indifferent, 31\% Accepting, 9\% Ambivalent, and 6\% Sceptical.

As compared to those classified as Accepting, more Indifferent participants smoked, had a healthy weight, lower TJCs, and trend for lower CDAI (Table). Groups were similar by sociodemographics, symptom duration, and DMARD/ steroid use, except fewer Indifferent patients received MTX. Indifferent patients had statistically and meaningfully lower patient global, depression, anxiety, fatigue and pain interference, and higher function and participation scores (Table).

Conclusion: Many new RA patients had low medication necessity beliefs and concerns, and only $31 \%$ had high necessity beliefs and low concerns around diagnosis. Lifestyle and lower CDAI, TJCs, symptoms and functional impacts were associated with RA medication indifference. Identifying medication indifference can prompt discussions about medication beliefs/concerns to facilitate shared decision-making and adherence.

\begin{tabular}{|c|c|c|c|c|c|}
\hline Mean (SD) or N (\%) & Accepting & Ambivalent & Sceptical & Indifferent & SIG \\
\hline $\mathrm{N}(\%)$ & $112(31 \%)$ & $34(9 \%)$ & $21(6 \%)$ & $195(54 \%)$ & - \\
\hline Age & $57(15)$ & $57(14)$ & $56(12)$ & 55 (15) & 0.518 \\
\hline Women & $68(62 \%)$ & $21(62 \%)$ & $14(70 \%)$ & $127(69 \%)$ & 0.605 \\
\hline Minority & $13(12 \%)$ & $8(24 \%)$ & $2(10 \%)$ & $36(20 \%)$ & 0.173 \\
\hline Education > HS & $69(62 \%)$ & $21(62 \%)$ & $12(57 \%)$ & $119(61 \%)$ & 0.862 \\
\hline Currently smoking & $10(9 \%)$ & $10(30 \%)$ & $4(20 \%)$ & $30(17 \%)$ & .010 \\
\hline Former smoker & $50(47 \%)$ & $13(39 \%)$ & $12(60 \%)$ & $62(35 \%)$ & \\
\hline Never smoked & $47(44 \%)$ & $10(30 \%)$ & $4(20 \%)$ & $87(49 \%)$ & \\
\hline Healthy BMI $(<25)$ & $8(28 \%)$ & $22(22 \%)$ & $6(33 \%)$ & $67(41 \%)$ & .036 \\
\hline Overweight (25-30) & $12(41 \%)$ & $47(46 \%)$ & $6(33 \%)$ & $46(28 \%)$ & \\
\hline Obese $(30+)$ & $9(31 \%)$ & $33(32 \%)$ & $6(33 \%)$ & $52(32 \%)$ & \\
\hline Symptom duration (m) & $5.3(2.8)$ & $5.1(2.9)$ & $5.1(3.2)$ & $5.8(3.0)$ & 0.411 \\
\hline Tender joint $(0-28)$ & $9(7)_{a}$ & $8(6)_{a, b}$ & $8(6)_{a, b}$ & $7(6)_{b}$ & 0.032 \\
\hline Swollen joint $(0-28$ & $8(6)$ & $7(5)$ & $8(5)$ & $6(5)$ & 0.203 \\
\hline CDAI & $26.8(12.5)_{\mathrm{a}}$ & $28.0(14.8)_{a, b}$ & $26.9(11.6)_{a, b}$ & $22.9(12.5)_{\mathrm{b}}$ & 0.011 \\
\hline Methotrexate & $91(81 \%)$ & $24(71 \%)$ & $15(71 \%)$ & $130(67 \%)$ & 0.057 \\
\hline Non-MTX DMARDs & $60(54 \%)$ & $20(59 \%)$ & $12(57 \%)$ & $105(54 \%)$ & 0.943 \\
\hline Oral steroids & $37(33 \%)$ & $10(29 \%)$ & $8(38 \%)$ & $46(24 \%)$ & 0.222 \\
\hline Parenteral steroids & $39(35 \%)$ & $11(32 \%)$ & $6(29 \%)$ & $59(30 \%)$ & 0.852 \\
\hline
\end{tabular}

\begin{tabular}{|c|c|c|c|c|c|c|c|c|c|}
\hline & \multicolumn{8}{|c|}{ BMQ Classification } & \multirow{3}{*}{ SIG } \\
\hline & \multicolumn{2}{|c|}{$\begin{array}{c}\text { Accepting } \\
\text { (High N Low C) }\end{array}$} & \multicolumn{2}{|c|}{$\begin{array}{c}\text { Ambivalent } \\
\text { (High N High C) }\end{array}$} & \multicolumn{2}{|c|}{$\begin{array}{c}\text { Sceptical } \\
\text { (Low N High C) }\end{array}$} & \multicolumn{2}{|c|}{$\begin{array}{c}\text { Indifferent } \\
\text { (Low N Low C) }\end{array}$} & \\
\hline & Mean & SD & Mean & SD & Mean & SD & Mean & SD & \\
\hline Patient Global $(0-10)$ & $5.2 \mathrm{a}$ & 2.7 & $6.0_{\mathrm{a}}$ & 2.9 & $5.8_{\mathrm{a}}$ & 2.6 & $4.4 \mathrm{~b}$ & 2.6 & $<0.0001$ \\
\hline Pain $(0-10)$ Vo & $5.8_{\mathrm{a}}$ & 2.8 & $7.0_{0}$ & 2.8 & $5.9_{a b}$ & 2.8 & $5.2_{\mathrm{a}}$ & 2.8 & 0.0013 \\
\hline PHQ8 Depression & $7.3 \mathrm{a}$ & 5.6 & $11.8_{\mathrm{b}}$ & 7.4 & $7.5 \mathrm{acc}$ & 6.6 & $5.4 \mathrm{c}$ & 5.0 & 0.0051 \\
\hline \multicolumn{10}{|l|}{ PROMIS-29 } \\
\hline Physical Function & $39.4 \mathrm{a}$ & 7.7 & $37.4 \mathrm{a}$ & 7.1 & $38.4 \mathrm{a}$ & 8.3 & $42.4 \mathrm{~b}$ & 7.9 & 0.0001 \\
\hline Depression & $51.9_{\mathrm{a}}$ & 9.6 & $57.9_{\mathrm{b}}$ & 11.5 & $56.9_{0}$ & 9.3 & $49.6_{\mathrm{c}}$ & 9.3 & $<0.0001$ \\
\hline Anxiety & $58.5 \mathrm{a}$ & 9.5 & 52.5 。 & 9.6 & $58.4_{\mathrm{a}}$ & 8.6 & $50.7_{b}$ & 9.7 & $<0.0001$ \\
\hline Fatigue & $55.7 \mathrm{a}$ & 10.2 & $57.7 \mathrm{a}$ & 10.4 & $54.9 a, b$ & 12.3 & $51.8_{\mathrm{b}}$ & 10.9 & 0.0018 \\
\hline Sleep Disturbance & 53.0。 & 8.8 & 54.5 & 6.7 & 55.4 & 6.8 & 53.0。 & 9.0 & 0.5367 \\
\hline Participation & $41.8_{\mathrm{a}}$ & 10.0 & $40.6_{a}$ & 10.2 & $40.8 \mathrm{ab}$ & 8.1 & $44.2 \mathrm{~b}$ & 9.6 & 0.0553 \\
\hline Pain Interference & $62.1_{a}$ & 7.8 & $64.1_{a}$ & 8.1 & $62.2 \mathrm{ab}$ & 8.5 & $58.9_{0}$ & 8.8 & 0.0004 \\
\hline
\end{tabular}

Note: Values in the same row with differing subscripts are significantly different $(p<0.05)$.
Disclosure of Interests: Viviane Ta: None declared, Orit Schieir: None declared, Marie-France Valois: None declared, Glen Hazlewood: None declared, Carol Hitchon Grant/research support from: UCB Canada; Pfizer Canada, Louis Bessette Grant/research support from: AbbVie, Amgen, Bristol-Myers Squibb, Celgene, Eli Lilly, Janssen, Merck, Novartis, Pfizer, Roche, Sanofi, UCB Pharma Consultant of: AbbVie, Amgen, Bristol-Myers Squibb, Celgene, Eli Lilly, Janssen, Merck, Novartis, Pfizer, Roche, Sanofi, UCB Pharma, Speakers bureau: AbbVie, Amgen, Bristol-Myers Squibb, Celgene, Eli Lilly, Janssen, Merck, Novartis, Pfizer, Sanofi, Diane Tin: None declared, Carter Thorne Consultant of: Abbvie, Centocor, Janssen, Lilly, Medexus/Medac, Pfizer, Speakers bureau: Medexus/ Medac, Janet Pope Grant/research support from: AbbVie, Bristol-Myers Squibb, Eli Lilly \& Company, Merck, Roche, Seattle Genetics, UCB, Consultant of: AbbVie, Actelion, Amgen, Bayer, Boehringer Ingelheim, Bristol-Myers Squibb, Eicos Sciences, Eli Lilly \& Company, Emerald, Gilead Sciences, Inc., Janssen, Merck, Novartis, Pfizer, Roche, Sandoz, Sanofi, UCB, Speakers bureau: UCB, Gilles Boire Grant/research support from: Merck Canada (Registry of biologices, Improvement of comorbidity surveillance)

Amgen Canada (CATCH, clinical nurse)

Abbvie (CATCH, clinical nurse)

Pfizer (CATCH, Registry of biologics, Clinical nurse)

Hoffman-LaRoche (CATCH)

UCB Canada (CATCH, Clinical nurse)

BMS (CATCH, Clinical nurse, Observational Study Protocol IM101664. SEROPOSITIVITY IN A LARGE CANADIAN OBSERVATIONAL COHORT)

Janssen $(\mathrm{CATCH})$

Celgene (Clinical nurse)

Eli Lilly (Registry of biologics, Clinical nurse), Consultant of: Eli Lilly, Janssen Novartis, Pfizer, Speakers bureau: Merck, BMS, Pfizer, Edward Keystone Grant/ research support from: AbbVie, Amgen, Bristol-Myers Squibb, F. Hoffmann-La Roche Inc, Gilead, Janssen Inc, Lilly Pharmaceuticals, Pfizer Pharmaceuticals, Sanofi-Aventis, Consultant of: AbbVie, Amgen, AstraZeneca Pharma, Biotest Bristol-Myers Squibb Company, Celltrion, Crescendo Bioscience, F. Hoffmann-La Roche Inc, Genentech Inc, Gilead, Janssen Inc, Lilly Pharmaceuticals, Merck, Pfizer Pharmaceuticals, Sandoz, UCB., Speakers bureau: Amgen, AbbVie, Bristol-Myers Squibb Canada, F. Hoffmann-La Roche Inc., Janssen Inc. Merck, Pfizer Pharmaceuticals, Sanofi Genzyme, UCB, Vivian Bykerk: None declared, Susan J. Bartlett Consultant of: Pfizer, UCB, Lilly, Novartis, Merck, Janssen, Abbvie, Speakers bureau: Pfizer, UCB, Lilly, Novartis, Merck, Janssen, Abbvie

DOI: 10.1136/annrheumdis-2020-eular.4328

\section{FRI0031 OBSERVATIONS ON BIOMARKERS IN VERY EARLY RHEUMATOID ARTHRITIS CONSECUTIVELY RECRUITED OVER 20 YEARS, FROM BASELINE PRESENTATION TO FIVE-YEAR OUTCOMES}

N. Carrier ${ }^{1}$, S. Roux ${ }^{2}$, A. Masetto ${ }^{2}$, A. J. Debrum Fernandes ${ }^{2}$, P. Liang ${ }^{2}$, M. Maoui ${ }^{3}, \mathrm{G}$. Boire ${ }^{2} .{ }^{1}$ Centre Intégré Universitaire de Santé et de Services Sociaux de l'Estrie - Centre Hospitalier Universitaire de Sherbrooke, Rheumatology, Sherbrooke, Canada; ${ }^{2}$ University of Sherbrooke - Health Campus, Medicine, Sherbrooke, Canada; ${ }^{3}$ Bristol-Myers Squibb Canada Co, Montréal, Canada

Background: Since July 1998, the Early Undifferentiated PolyArthritis (EUPA) cohort recruited consecutive adults with recent-onset immune-mediated polyarthritis ${ }^{1,2}$. Patients were treated aiming at 0 swollen joint.

Objectives: To analyze the impact of biomarkers over 20 years on baseline variables, treatments, comorbidities and outcomes over the first 5 years of follow up.

Methods: Variables and Outcomes were collected over 5 years in consecutive patients fulfilling RA criteria, grouped according to date of inclusion (Period 1: 1998-2004; Period 2: 2005-2010; Period 3: 2011-2018). Comparisons of baseline characteristics, treatment, and outcomes over 5 years between the 3 Periods were previously presented (ACR 2018 and 2019). Erosive damage was scored according to Sharp/van der Heijde; erosive status was defined as $\geq 5$ Erosion units. We now present observed associations between the presence of baseline prognostic biomarkers (anti-CCP2 (ACPA), RF, anti-Sa, and erosive status) with concomitant and subsequent disease activity levels, radiographic scores, comorbidities and impact of treatment. False discovery rate correction was used to adjust $\mathrm{p}$-values for multiple comparisons.

Results: 753 patients were included: 247, 263 and 243 in Periods 1, 2 and 3 , respectively. Variables at baseline. No biomarkers, including erosive status, were associated with demographics or disease activity. Erosive disease was more prevalent in ACPA+ $(19.9 \%$ vs $13.9 \%, p=0.0417)$. Current smoking decreased by period $(20.6,17.2,8.6 \% ; p=0.02)$ in ACPA negatives only, remaining stable among ACPA+ $(25.3,20.9,18.8 \%$, NS). All comorbidities were significantly more present in ACPA negatives vs positives (RR between 1.55 and 1.99). Prevalence of cardiovascular (CV; 44.8, 55.0, 60.0\%; $\mathrm{p}=0.036)$ and cancer $(4.1,7.1,13.1 \%$; 
$\mathrm{p}=0.02)$ comorbidities increased over time in ACPA negatives and remained stable in ACPA+ (CV: 33.0, 30.8, 40.7, NS; cancer: 3.0, 4.4, 6.2, NS). RF positivity decreased by period $(47.8,36.9,36.7 \%, p=0.03)$, but ACPA+ remained stable $(40.8,35,35.4 \% \mathrm{NS})$.

Outcomes over 5 years of follow up.

There was no link between the presence of any biomarker and subsequent disease activity scores. Positive ACPA, RF and anti-Sa at baseline predicted development of more erosive status ( $R R=1.50 ; 1.37$ and 1.52 , all $p<0.001$ ). $68 \%$ reached DAS28 remission overall $(70.3 \%$ in ACPA negatives, $65.2 \%$ in ACPA+). Independent of ACPA status, remission rates increased between Periods 1 vs $2(R R=1.14, p=0.04)$ and 1 vs $3(R R=1.13, p=0.055)$, but not between 2 vs 3 . CV comorbidities among ACPA+ increased significantly more over time vs ACPA negatives $(+8.9 \%$ vs $+4.1 \%$; $R R=1.18, p=0.03)$. Erosion scores increased significantly more in ACPA+ treated with DMARDs only vs receiving a biologic ( $\Delta$ Sharp: 3.98 vs $3.11, p=0.026 ; \Delta$ Erosions: 2.58 vs 1.83 , $p=0.02$ ). By period, erosive status decreased significantly (Periods 2 vs $1: R R=$ $0.65, p=0.002$; 3 vs 1 : $R R=0.42, p=0.002 ; 3$ vs 2 : $R R=0.64, p=0.007$ ), both in $\mathrm{ACPA}+$ and negatives.

Conclusion: In this cohort of recent onset $\mathrm{RA}$ recruited over 20 years, we observed a constant drift towards RF-negative arthritis at baseline with decreasing smoking rates and increasing comorbidities in seronegative patients. Positive antibodies were associated more cardiovascular comorbidities accrual. Autoantibody positive (especially ACPA+) patients developed more erosive disease and had better erosion outcomes with biologic treatments. Irrespective of the presence or absence of biomarkers, marked improvements in control of disease activity and in remission rates occured over each period.

References:

[1] Boire G, et al. Arthritis Res Ther 2005;7:R592-R603;

[2] Carrier N, et al. Arthritis Res Ther 2016;18:37

Disclosure of Interests: Nathalie Carrier: None declared, Sophie Roux: None declared, Ariel Masetto: None declared, Artur J. deBrum Fernandes: None declared, Patrick Liang: None declared, Meryem Maoui Employee of: Bristol Myers Squibb Canada, Gilles Boire Grant/research support from: Merck Canada (Registry of biologices, Improvement of comorbidity surveillance)

Amgen Canada (CATCH, clinical nurse)

Abbvie (CATCH, clinical nurse)

Pfizer (CATCH, Registry of biologics, Clinical nurse)

Hoffman-LaRoche (CATCH)

UCB Canada (CATCH, Clinical nurse)

BMS (CATCH, Clinical nurse, Observational Study Protocol IM101664. SEROPOSITIVITY IN A LARGE CANADIAN OBSERVATIONAL COHORT)

Janssen (CATCH)

Celgene (Clinical nurse)

Eli Lilly (Registry of biologics, Clinical nurse), Consultant of: Eli Lilly, Janssen, Novartis, Pfizer, Speakers bureau: Merck, BMS, Pfizer

DOI: 10.1136/annrheumdis-2020-eular.717

\section{FRI0032 REGIONAL AND WIDESPREAD PATTERNS OF NON-ARTICULAR PAIN ARE COMMON AT RA DIAGNOSIS AND CONTRIBUTE TO POOR OUTCOMES AT 12 MONTHS: A PROSPECTIVE STUDY OF PAIN PATTERNS IN CANADIANS WITH RA}

V. Bykerk ${ }^{1}$, O. Schieir ${ }^{2}$, M. F. Valois ${ }^{3}$, L. Bessette ${ }^{4,5}$, G. Boire ${ }^{6}$, G. Hazlewood ${ }^{7}$, C. Hitchon ${ }^{8}$, E. Keystone ${ }^{2}$, D. Tin ${ }^{9}$, C. Thorne ${ }^{9}$, J. Pope ${ }^{10}$, S. J. Bartlett ${ }^{3}$ on behalf of CATCH Investigators. ${ }^{1}$ Hospital for Special Surgery, New York, United States of America; ${ }^{2}$ University of Toronto, Toronto, Canada; ${ }^{3}$ Mc Gill University, Montreal, Canada; ${ }^{4}$ Laval University and $\mathrm{CHU}$ de Quebec, Quebec City, Canada; ${ }^{5}$ Centre de l'Ostéoporose et de Rhumatologie de Québec, Department of Medicine,
Quebec City, Canada; ${ }^{6}$ University of Sherbrooke, Faculty of Medicine and Health Sciences, Sherbrooke, Canada; ${ }^{7}$ University of Calgary, Calgary, Canada; ${ }^{8}$ University of Manitoba, Winnipeg, Canada; ${ }^{9}$ Southlake Regional Health Center, Newmarket, Canada; ${ }^{10}$ University of Western, London, Canada

Background: Persistent pain can occur in early RA patients, despite improvement in synovitis and may be due to coexisting non-articular pain (NAP). Though NAP is often attributed to fibromyalgia and widespread NAP, regional NAP syndromes may be more common and under-recognized.

Objectives: To describe patterns of NAP, predictors of persistent NAP and impact on outcomes in the first year following early RA diagnosis.

Methods: Data were from participants enrolled in the Canadian Early Arthritis Cohort (CATCH) between 2017-2019 who completed 0,6,12-month evaluations with patient-reported outcomes [PROs] and clinical data available. We used the McGill Body Pain Diagram (BPD) to classify patients as experiencing no NAP, regional (RP:1-2 regions) or widespread NAP (WP:3-5 regions). Multinomial regression was used to identify baseline predictors of persistent RP and WP at 12-months. Multi-adjusted GEE with linear and logit links were used to estimate time-varying associations of NAP patterns with outcomes updated at each time point.

Results: Study included 421 participants: $66 \%$ were female, with a mean(sd) age 56 (14); $72 \%$ were seropositive and $90 \%$ were treated with MTX \pm csDMARDs as initial therapy. NAP at baseline was common (55\%), with majority (62\%) reporting regional NAP. NAP prevalence was $33 \%$ at 12 months (Figure). Female sex and baseline depressive symptoms were independent predictors of widespread NAP at 12 months while poorer function and lack of early MTX treatment independently predicted regional NAP, at 12 mos. Regional and widespread NAP were associated with lower likelihood of remission in adjusted models that accounted for changes in NAP and remission over time (Table).

Conclusion: NAP is commonly reported in early RA pts seen in real world settings. Regional NAP was more common than WSP at all time-points, but both NAP patterns were associated lower odds of achieving remission targets by 12 months. These data support considering the role of NAP when assessing RA treatment efficacy during clinical visits and warrant different treatment approaches to reduce symptoms in RA patients receiving target-based care.

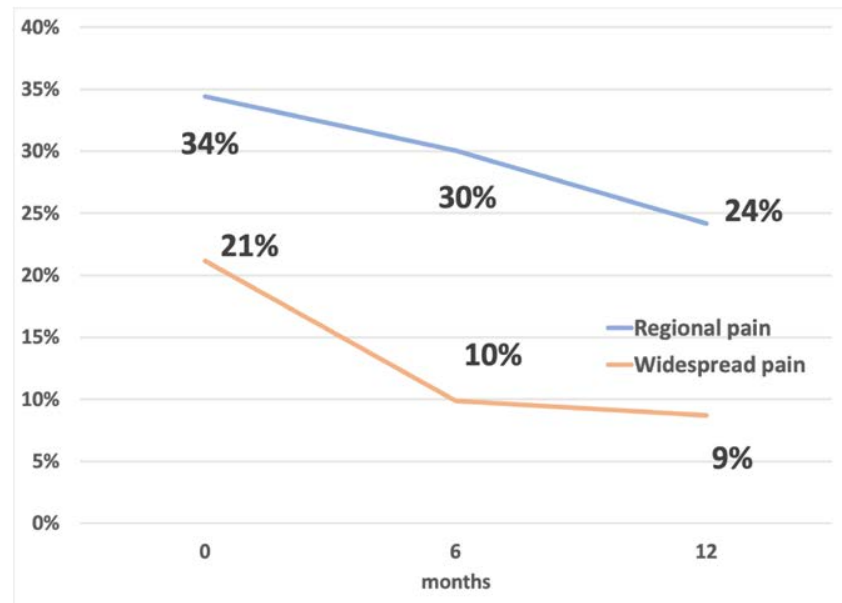

Figure. Point prevalence of regional and widespread NAP at baseline, 6 and 12 months.

Table. Results of Multi-Adjusted GEE Logistic Regression showing Regional and Widespread NAP is associated with a reduced likelihood of achieving Stringent Remission Targets

Boolean Remission Outcome

Disease stage and Clinical Disease Activity Regional vs No NAP Widespread vs No NAP Age

Women vs Men

$\mathrm{RDCl}^{\phi}$ at baseline

Symptom duration

Seronegative vs ACPA+/RF

MTX in first 3 months

Oral Steroids in first 3

months

\begin{tabular}{lc}
\hline Age/sex adjusted & Fully \\
$\mathrm{OR}(95 \% \mathrm{Cl})$ & Adjusted
\end{tabular}

Adjusted

$0.41(0.20,0.83)$

$0.27(0.08,0.85)$

$1.01(0.98,1.04)$

$0.76(0.41,1.42)$

$0.91(0.73,1.14)$

$0.96(0.86,1.08)$

$1.15(0.60,2.19)$

$1.51(0.73,3.13)$

$0.53(0.25,1.10)$

SDAI Remission Outcome

Age/sex adjusted $\quad$ Fully Adjusted

OR $(95 \% \mathrm{Cl})$

$0.41(0.23,0.71)$

$0.23(0.09,0.61)$

$\mathrm{NI}$

$\mathrm{NI}$

$\mathrm{NI}$

$\mathrm{NI}$

$\mathrm{NI}$
$0.55(0.30,1.00)$

$0.29(0.11,0.80)$

$1.01(0.98,1.03)$

$0.69(0.37,1.27)$

$0.90(0.74,1.10)$

$1.00(0.90,1.10)$

$1.43(0.79,2.60)$

$1.20(0.64,2.24)$

$0.44(0.22,0.87)$

${ }^{\phi} \mathrm{RDCl}=$ rheumatic disease comorbidity index 